\title{
Actinomycosis in a gray four-eyed opossum (Philander opossum) caused by a novel species of Schaalia
}

Stefanie Knoepfler ${ }^{1}$, Alexandria Schauer ${ }^{2}$, Andreas Thomann ${ }^{1}$, Simon Feyer ${ }^{1}$, Peggy Rüegg-van den Broek ${ }^{3}$, Olivier Jean Glardon ${ }^{3}$ and Sonja Kittl ${ }^{1^{*}}$

\begin{abstract}
Background: Infective lesions of the jaws and adjacent tissues (lumpy jaw disease, LJD) have been recognized as one major cause of death of captive macropods. Fusobacterium necrophorum and Actinomyces species serve as the main source of LJD in kangaroos and wallabies. Currently, little is reported about LJD or similar diseases in opossums.

Case presentation: Here we report a case of actinomycosis resembling the entity lumpy jaw disease in a gray foureyed opossum, caused by a novel species of Schaalia. A 2.8 year old male Philander opossum was presented with unilateral swelling of the right mandible. After an initial treatment with marbofloxacin, the opossum was found dead the following day and the carcass was submitted for necropsy. Postmortem examination revealed severe mandibular skin and underlying soft tissue infection with subsequent septicemia as the cause of death. Histological examination demonstrated Splendore-Hoeppli phenomenon, typically seen in classical cases of actinomycosis. Bacteriology of liver and mandibular mass yielded a previously undescribed species of Schaalia, whose $16 \mathrm{~S}$ rRNA gene sequence was $97.0 \%$ identical to Schaalia canis. Whole genome sequencing of the opossum isolate and calculation of average nucleotide identity confirmed a novel species of Schaalia, for which no whole genome sequence is yet available.

Conclusions: The herewith reported Schaalia infection in the gray four-eyed opossum resembling classical actinomycosis gives a novel insight into new exotic animal bacterial diseases. Schaalia species may belong to the normal oral microbiome, as in macropods, and may serve as a contributor to opportunistic infections. Due to the lack of current literature, more insights and improved knowledge about Schaalia spp. and their pathogenicity will be useful to choose appropriate therapy regimens and improve the treatment success rate and outcome in exotic and endangered species.
\end{abstract}

Keywords: Gray four-eyed opossum (Philander opossum), lumpy jaw disease, Schaalia, actinomycosis

\footnotetext{
* Correspondence: sonja.kittl@vetsuisse.unibe.ch

'Institute of Veterinary Bacteriology, Vetsuisse Faculty, University of Bern, 122 Laenggassstrasse, $\mathrm{CH}-3012$ Bern, Switzerland

Full list of author information is available at the end of the article
}

(c) The Author(s). 2021 Open Access This article is licensed under a Creative Commons Attribution 4.0 International License, which permits use, sharing, adaptation, distribution and reproduction in any medium or format, as long as you give appropriate credit to the original author(s) and the source, provide a link to the Creative Commons licence, and indicate if changes were made. The images or other third party material in this article are included in the article's Creative Commons licence, unless indicated otherwise in a credit line to the material. If material is not included in the article's Creative Commons licence and your intended use is not permitted by statutory regulation or exceeds the permitted use, you will need to obtain permission directly from the copyright holder. To view a copy of this licence, visit http://creativecommons.org/licenses/by/4.0/ The Creative Commons Public Domain Dedication waiver (http://creativecommons.org/publicdomain/zero/1.0/) applies to the data made available in this article, unless otherwise stated in a credit line to the data. 


\section{Background}

The family of the Actinomycetaceae is comprised by a heterologous group of anaerobic or facultative anaerobic, asporogenous, non-acid-fast, filamentous or diphtheroid, rod-shaped organisms with a high DNA G + C content [1]. Among the most relevant genera in veterinary medicine are Actinomyces, Schaalia, Actinobaculum and Trueperella.[2].

The genus Actinomyces is one of the largest genera within the Actinomycetaceae [3].

Actinomyces species are ubiquitous, and can be found in soil and in the microbiota of animals and humans. While certain species are commensal in the skin flora and on mucus membranes, others are major pathogens, leading to intrinsic infections in humans and animals. Severe diseases in veterinary medicine are mostly associated with $A$. bovis, $A$. viscosus, A. hordeovulneris and $A$. hyovaginalis, whereas $A$. israelii is considered the primary pathogen affecting humans [2]. The causative Actinomyces species typically gain access to deeper tissue through trauma, surgical procedures or foreign bodies, which compromise the mucosal barrier. Within different tissues, the bacteria form masses consisting of aggregates of branching, filamentous bacilli and lead to chronic, pyogranulomatous reactions [4].

Other than fimbriae, peptidoglycan and biofilm production, as described in human cases, relatively little is known about virulence traits in the genus Actinomyces [5]. Specific virulence factors of Actinomyces species of veterinary importance have not yet been identified [2]

Actinomyces species are fastidious and thus not easy to culture and isolate. They grow slowly on sheep blood agar at $37{ }^{\circ} \mathrm{C}$ under capnophilic and/or anaerobic conditions. Colonies are grossly visible in approximately two days and appear mostly very small, with a maximum diameter of one millimeter. Furthermore, they are generally non-hemolytic, white, rough or smooth and can adhere tenaciously to solid medium. Within Gram-stained smears, bacteria are Gram-positive and appear as slightly branched filaments or short forms. On subculture, the bacteria may become diphtheroidal or coccobacillary [2].

Demonstration of Gram-positive-staining, filamentous organisms and sulfur granules on histological examination is strongly suggestive of a diagnosis of actinomycosis. However, isolation and identification of Actinomyces by conventional methods is often difficult and time consuming. The sequence analysis of the $16 \mathrm{~S}$ rRNA gene and, in recent years, matrix-assisted laser desorption/ ionization time-of-flight mass spectrometry (MALDITOF-MS) has become a rapid and simple method to identify Actinomyces species [6, 7].

$16 \mathrm{~S}$ rRNA gene sequencing has shown the genus Actinomyces to be very heterogeneous and phylogenetically intermixed with other genera such as
Arcanobacterium and Mobiluncus [8, 9]. In 2018, some of the species were, according to the phylogenomic data, emended to the genera of Bowdenia, Boudabousia, Buchananella, Gleimia, Pauljensenia, Schaalia and Winkia [10]. This also applies to Actinomyces canis, first isolated from skin and mucous membranes of three dogs, which has been reclassified to the new genus Schaalia $[10,11]$. Currently, the genus Schaalia is comprised of 12 published species (www.lpsn.dsmz.de, accessed 08.07.2020).

Here we report a case of actinomycosis caused by a novel species of the genus Schaalia. The species was isolated from a subcutaneous mandibular mass, liver and lung of a gray four-eyed opossum (Philander opossum). The gray four-eyed opossum is one of many opossum species in the order Didelphimorphia and the family Didelphidae. P. opossum is a neotropical marsupial, ranging in distribution from northeastern Mexico to southeastern Brazil. The habitat includes mainly tropical forest areas, such as tropical evergreen, secondary growth and gallery forests. Gray four-eyed opossums are primarily nocturnal, omnivorous and have a life span of up to 2.5 years and 3.5 years in the wild and in captivity, respectively $[12,13]$.

Not only is information regarding disease processes in the gray four-eyed opossum scarce, insights regarding Schaalia spp. infections and their pathogenicity is, to our knowledge, nonexistent. In other marsupial families (including kangaroos and wallabies), progressive pyogranulomatous osteomyelitis involving the mandible or maxilla (lumpy jaw disease, LJD) is a common bacterial disorder and is one of the most significant causes of illness and death in captive macropods [14]. The jaw infection is characterized by swelling around the face and jaw, sometimes involving mandibular lymph nodes and salivary glands. Fusobacterium necrophorum serves as the main source of LJD, whereas Actinomyces spp. and Corynebacterium spp. are less commonly isolated bacterial agents [15]. A bacteremia may result in systemic disease, disseminating organisms to other organs, including liver and lungs, as seen in the presently described case [15]. We report the isolation of a new species of Schaalia associated with mandibular skin and soft tissue infection, resulting in septicemia and death in a gray four-eyed opossum.

\section{Case presentation}

The 2.8 year old male Philander opossum was housed in a group of five members, including two parents and three offspring in an indoor enclosure in a zoo near Bern, Switzerland, and served as the sire of the group. The group had been gifted to the zoo two years before and had been living there ever since. The animal was presented to the zoo veterinarian for evaluation of a 


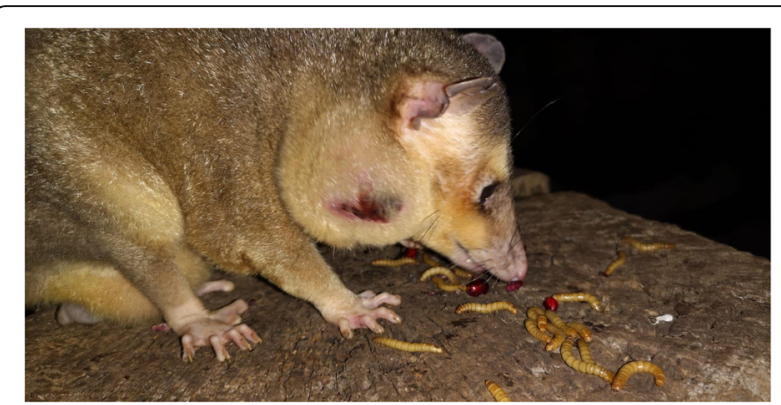

Fig. 1 Male Philander opossum with unilateral ulcerated swelling of the right mandible

unilateral swelling in the area of the right mandible (Fig. 1), which eventually developed ulceration. The opossum was otherwise clinically sound. After ulceration occurred, initial treatments were performed that consisted of rinsing and local disinfection, as well as administration of an oral anti-inflammatory agent (meloxicam, $0.02 \mathrm{mg} / \mathrm{kg}$, started several days later). Although the swelling appeared to ameliorate, the wound never fully closed, three weeks after initial treatments, oral antibiotic therapy consisting of marbofloxacin at a dose of $2.6 \mathrm{mg} / \mathrm{kg}$ was initiated. The next day, the opossum was found dead, despite having shown no additional premonitory clinical signs.

The carcass was submitted to the Institute of Animal Pathology at the University of Bern for postmortem examination. On gross examination, a focally extensive swelling of $3 \times 2.5 \times 1.5 \mathrm{~cm}$ was present on the caudolateral aspect of the mandible with a superficial, focal ulceration of $1.3 \times 1.0 \mathrm{~cm}$. On cut section, the swelling was located subcutaneously and was comprised of a welldemarcated, encapsulated, non-movable mass with an inhomogeneous, firm to friable, white to yellow cut surface. Histopathological examination demonstrated central areas of necrosis in addition to large, multifocal accumulations of intensely eosinophilic material arranged in radiating, club-like structures (SplendoreHoeppli phenomenon), admixed with abundant filamentous bacterial rods (Fig. 2). This material was surrounded by high numbers of neutrophils, surrounded by macrophages, few multinucleated giant cells, and a thick, fibrous connective tissue capsule, characteristic of a pyogranuloma. Samples of other visceral organs, including lung, spleen, liver, and kidney revealed acute, neutrophilic inflammation, consistent with septicemia. Furthermore, there was abundant perivascular deposition of amorphous, extracellular, acellular, pale eosinophilic material, which displays green birefringence following polarisation in Congo-red staining (compatible with amyloid [16]) within the spleen and kidney. Systemic reactive amyloidosis, particularly visualized in the spleen, kidneys, and liver, is a common sequela to sustained, chronic inflammation in other domestic and wild veterinary species [16], and should be taken into consideration as the cause in the presented case. However, because information regarding the four-eyed opossum is scarce, further structural investigations are necessary to classify the type of amyloid.

Samples of the subcutaneous mass, lung and liver were sent to the Institute of Veterinary Bacteriology, Vetsuisse Faculty, University of Bern (Switzerland) for bacteriological examination. The subcutaneous mass, lung and liver were cultured aerobically on Trypticase Soy Agar II with $5 \%$ Sheep Blood (BD) at $37{ }^{\circ} \mathrm{C}$ in a $5 \% \mathrm{CO}_{2}$ atmosphere. In addition, Brolac Agar plates (ThermoFisher) were used for the subcutaneous mass and liver, whereas MacConkey Agar (ThermoFisher) was used for lung tissue at $37{ }^{\circ} \mathrm{C}$ under aerobic conditions.

After incubation of the samples from liver and mandibular mass for $48 \mathrm{~h}$, more than 100 colonies of very small (approximately $1 \mathrm{~mm}$ in diameter), convex, opaque, milky white, non-hemolytic appearance could be

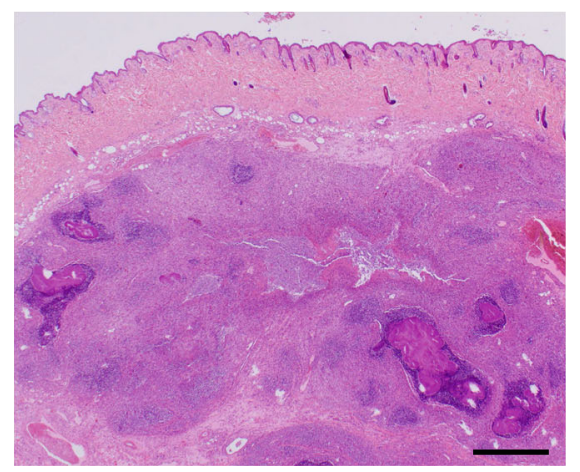

A

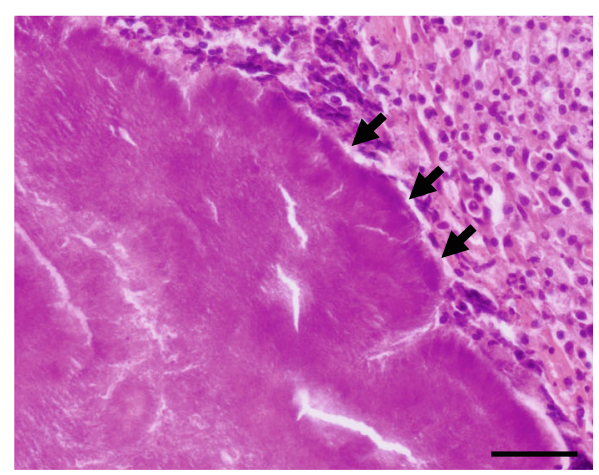

B

Fig. 2 Histopathological examination of the subcutaneous mass, stained with hematoxylin and eosin. A Low magnification demonstrating characteristic pyogranulomatous inflammation. Scale bar $=1 \mathrm{~mm}$. B Higher magnification, demonstrating dense mats of filamentous bacterial colonies (arrows) embedded in radiating, brightly eosinophilic material (Splendore-Hoeppli phenomenon). Scale bar $=50 \mu m$ 
detected (isolate 19OD2882) in addition to a smaller quantity of $\beta$-hemolytic streptococci (Streptococcus didelphis) and Pasteurella multocida. A lower number of the same colonies was visible on sheep blood agar from the lung. No growth was visible on Brolac and MacConkey Agar.

Gram stain performed on the most abundant bacterial colonies showed Gram-positive, non-spore-forming rods, which appeared coccobacillary after culture in an aerobic atmosphere enriched with $5 \% \mathrm{CO}_{2}$, and slightly branched filamentous from anaerobic culture. Phenotypically, the CAMP test and catalase activity were negative. Identification of strain 19OD2882 was not possible with Maldi-Tof MS (MALDI Biotyper, Bruker using the MTB 7845 MSP Library and an in-house library) or VITEK 2 CBC card (Biomérieux).

The 16S rRNA gene was amplified using universal primers [17]. Sequence query using NCBI BLASTN, database: "16S ribosomal RNA sequences" [18] showed the highest identity with Schaalia canis (97.0\%). When using database "Nucleotide collection," 99.9\% identity was observed with accession: KF030212.1 Actinomyces sp. canine oral taxon 417, a thus far undescribed species, isolated from a dog in the United Kingdom.

In order to confirm the classification of this isolate as a previously undescribed species and to verify its taxonomic position, whole genome sequencing using PacBio technology was performed. gDNA was extracted following the protocol of Pitcher et al.[19] and then submitted for sequencing to the Lausanne Genomic Technologies Facility (University of Lausanne, Switzerland). Genome assembly was performed using Canu 1.9 [20] followed by polishing with arrow (SMRT Link v7.0.0, Pacific Biosciences) and circularization with Circlator 1.5.5 [21]. The genome has a size of $2.56 \mathrm{Mb}$ and a GC content of $67.4 \%$. The genome sequence was deposited in GenBank (Accession: CP065521).

A phylogenetic tree from the $16 \mathrm{~S}$ rRNA sequence as well as the whole genome was generated using the Type (Strain) Genome Server [22]. In both phylogenies, 19OD2882 showed the closest relationship with Schaalia canis (Figs. 3 and 4).

Average nucleotide identity (ANI), which is a reliable method for species differentiation, was calculated using Oat version 0.93.1 which employs the OrthoANI algorithm [26]. The cut-off for species discrimination is normally set at $95 \%[27,28]$. ANI between 19OD2882 and Schaalia canis (NZ_RQZF01000001.1) was $71.3 \%$ while it was $73.8 \%$ with "Actinomyces polynensis" (NZ CCXH01000001.1), both well below the cut-off. Thus, 19OD2882 clearly constitutes a previously undescribed species of Schaalia possibly identical to "Actinomyces sp. canine oral taxon 417" for which no whole genome sequence is currently reported.

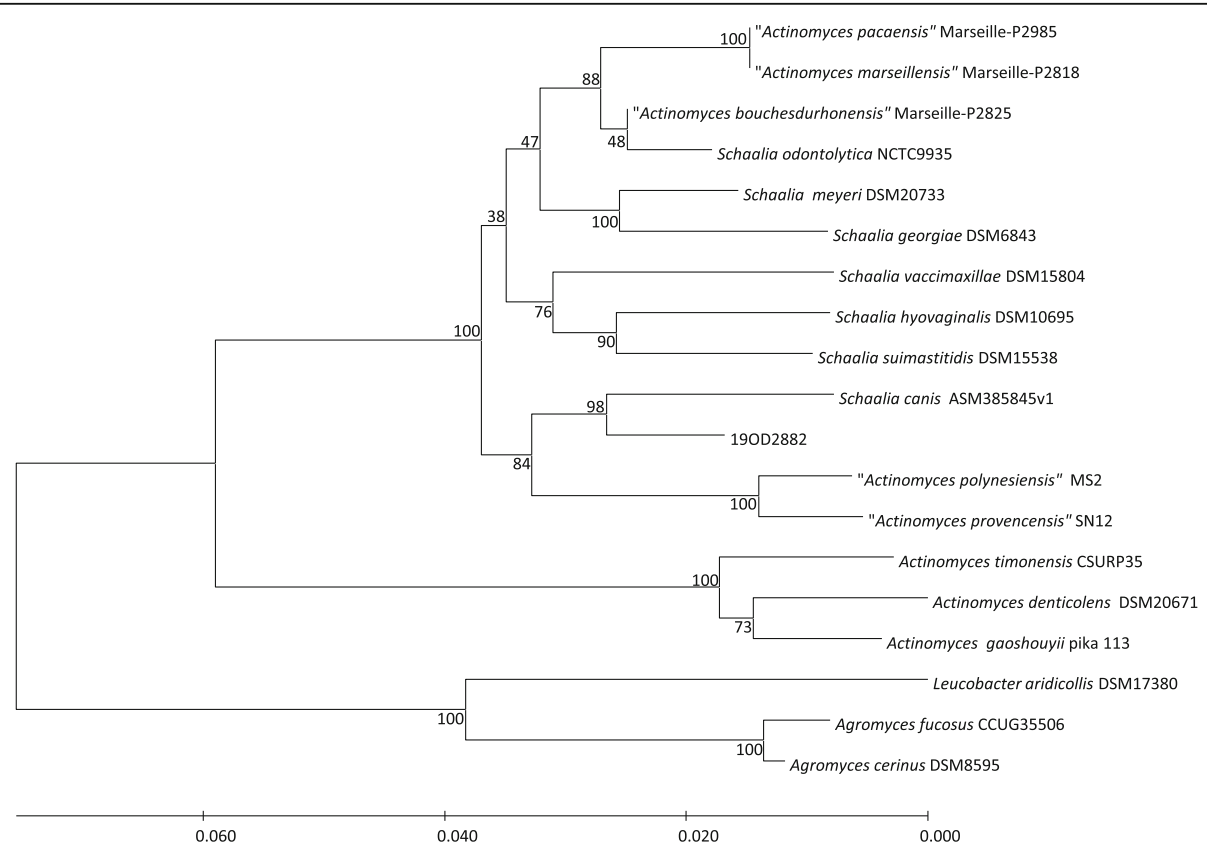

Fig. 3 Phylogenetic tree based on $16 \mathrm{~S}$ rRNA gene sequences. The tree was generated by the Type (Strain) Genome Server [22, 23] Tree inferred with FastME 2.1.6.1 [24] from Genome BLAST Distance Phylogeny approach (GBDP) distances calculated from 16S rRNA gene sequences. The branch lengths are scaled in terms of GBDP distance formula $d 5$ [25]. The numbers above branches are GBDP pseudo-bootstrap support values. Species not validly published are indicated in quotes 


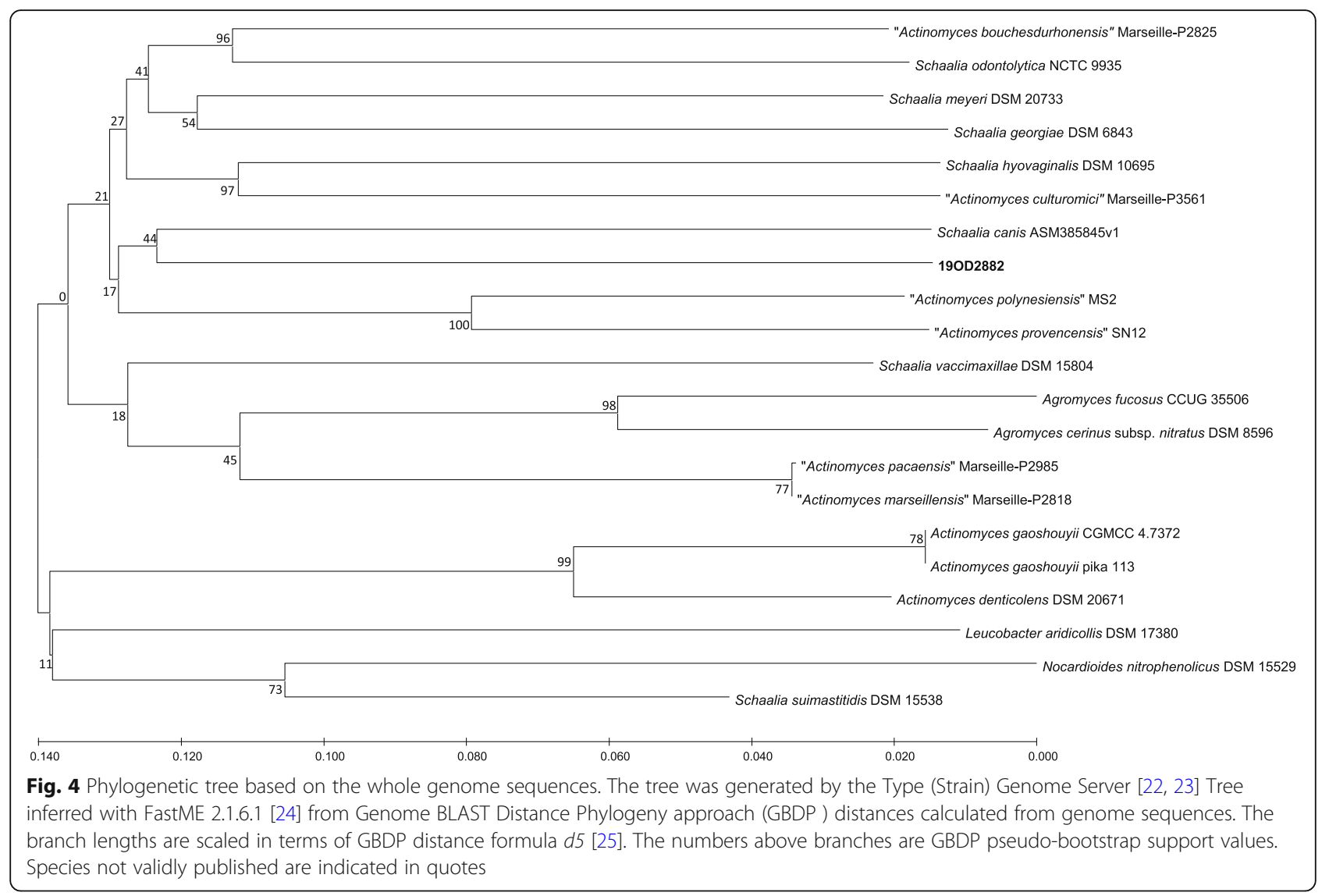

The isolate was tested for antimicrobial resistance by determination of minimum inhibitory concentrations (MIC) using Sensititre plates (ANO2B, Fisher Scientific AG, Reinach, Switzerland) and following EUCAST (European Committee on Antimicrobial Susceptibility Testing) guidelines for Gram-positive anaerobes, which are recommended for all Actinomyces spp. [29]. Briefly, the bacteria were cultured on sheep blood agar at $37^{\circ} \mathrm{C}$ under anaerobic conditions for $48 \mathrm{~h}$. They were then suspended in Mueller-Hinton broth with $5 \%$ lysed horse blood (Fisher Scientific AG, Reinach, Switzerland) at a concentration of $10^{5} \mathrm{CFU} / \mathrm{ml}$ and used for plate inoculation. The isolate was resistant to metronidazole but susceptible to all other antimicrobials tested. (Table 1).

\section{Discussion and conclusion}

Lumpy jaw disease (LJD) is a well-known bacterial infection in marsupial species. The primary cause of LJD in the macropod marsupials is considered to be Fusobacterium necorphorum. While, Actinomyces spp. are capable of producing lesions in bone, their role in "jaw disease" remains undefined. However, anaerobic actinomycetes were isolated in pure culture from jaw lesions in macropods [30].

Table 1 Minimal inhibitory concentrations for 190D2882, interpretation according to EUCAST clinical breakpoints where available

\begin{tabular}{lll}
\hline Antimicrobial & MIC $(\mathbf{m g} / \mathbf{L})$ & Interpretation \\
\hline Ampicillin/sulbactam (2:1 ratio) & $<0.5 / 0.25$ & $\mathrm{~S}$ \\
Cefotetan & $<4$ & - \\
Imipenem & $<0.12$ & $\mathrm{~S}$ \\
Clindamycin & $<0.25$ & $\mathrm{~S}$ \\
Metronidazole & 8 & $\mathrm{R}$ \\
Ampicillin & $<0.5$ & $\mathrm{~S}$ \\
Tetracycline & $<0.25$ & - \\
Piperacillin/ tazobactam (constant 4) & $<0.25 / 4$ & $\mathrm{~S}$ \\
Penicillin & $<0.06$ & $\mathrm{~S}$ \\
Amoxicillin/ clavulanic acid 2:1 ratio & $<0.5 / 0.25$ & $\mathrm{~S}$ \\
Cefoxitin & $<1$ & - \\
Chloramphenicol & $<2$ & $\mathrm{~S}$ \\
Piperacillin & $<4$ & - \\
Mezlocillin & $<4$ & - \\
Meropenem & $<0.5$ & $\mathrm{~S}$ \\
\hline
\end{tabular}


As actinomycetes are physiological inhabitants of the oral cavity and pharynx, the source of infections with these organisms tends to be endogenous, and mostly associated with trauma to the alveolar region or oral mucosa [31]. In veterinary medicine, studies mostly focus on the composition of the canine oral microbiome, in which the opportunistic pathogens Actinomyces and Fusobacterium spp. are reported to be highly abundant [32]. Oral microbiome constituents of most other veterinary species have not yet been well described. In marsupial species, Actinomyces spp. was recovered from $46 \%$ of samples from the healthy, oral mucosa [30]. Given this knowledge, it can be assumed that these bacterial species also belong to the normal oral microbiome of macropods and may lead to opportunistic actinomycosis. However, according to our knowledge, little is known regarding oral flora or pathogenicity of Actinomyces spp. in Philander opossum.

Streptococcus didelphis was also isolated from the subcutaneous mass, liver and lung tissue of the here described gray four-eyed opossum, albeit in a lower concentration than the Schaalia sp.. In one report, these $\beta$-hemolytic streptococci were first found in lung, kidney, liver, spleen and skin lesions from nine opossums presenting with skin lesions, followed by sudden death [33]. Primary lesions in these animals included liver fibrosis and suppurative necrotizing dermatitis, cellulitis and myonecrosis [33]. Due to this, it cannot be entirely excluded from consideration whether Streptococcus didelphis may also have played a role in development of disease. However, lesions of the present case demonstrated a primarily pyogranulomatous reaction with typical Splendore-Hoeppli phenomenon associated with actinomycosis, and suggests that the novel Schaalia sp. was most probably the main pathogen in this case.

Furthermore, little is currently known regarding virulence traits in the genus Actinomyces. Whether fimbriae, peptidoglycan and biofilm production, as described in human cases, can lead to systemic involvement and death in animals, remains unclear [2].

According to $16 \mathrm{~S}$ rRNA gene sequences, isolate 19OD2882 clearly belonged to a new species of the genus Schaalia, recently split from Actinomyces following comprehensive genetic analyses [10]. Interestingly, the 16S rRNA closely matched KF030212.1 Actinomyces sp. canine oral taxon 417 , indicating that this bacterial species is also part of the oral microbiome of dogs.

This case presentation could be of great interest for zoo veterinarians, especially with regard to treatment options of actinomycosis in the opossum. In human medicine, actinomycosis is treated with long term antibiotics, and according to current literature, antibiotic resistance seems to not play a role. Actinomyces spp. do not produce betalactamases and often are susceptible to beta-lactams antibiotics, most notably amoxicillin and penicillin G [34] Most strains are expected to be resistant to metronidazole, such as the presently isolated strain 19OD2882 [34, 35]. Fluoroquinolones, as applied once in this case, are not considered clinically effective against Gram-positive anaerobes including actinomycetes $[29,35]$.

Long-time therapy of approximately six months duration with oral clindamycin syrup $(11 \mathrm{mg} / \mathrm{kg}$ twice a day) has been demonstrated to be effective in treating kangaroo lumpy jaw cases. Clindamycin capsules are also available, but have a bitter taste and are not palatable to most kangaroos [15].

This first report of a case of a Schaalia-infection in the gray four-eyed opossum gives an interesting insight into exotic animal bacterial diseases, and may hopefully encourage veterinarians and veterinary researchers alike to explore and expand this field further. Better knowledge about bacterial species and their pathogenicity in wildlife will be helpful to choose appropriate therapies, and to ultimately improve clinical outcomes, particularly for exotic and endangered species.

\section{Abbreviations \\ LJD: Lumpy Jaw Disease ; ANI: Average Nucleotide Identity; EUCAST: European Committee on Antimicrobial Susceptibility Testing; MALDI-TOF-MS: Matrix-assisted laser desorption/ionization time-of-flight mass spectrometry; MIC: Minimum Inhibitory Concentration}

\section{Acknowledgements}

We thank Isabelle Brodard for DNA extraction. Calculations were performed on UBELIX (http://www.id.unibe.ch/hpc), the HPC cluster at the University of Bern.

\section{Authors' contributions}

Conceptualization, S.Ki. and S.Kn.; Formal Analysis, S.Ki. and S. F.; Investigation, S. Kn, A.S., A.T., S.F. and S. Ki; Resources, P.R. and O.G.; Writing - Original Draft Preparation, S.Kn., A.S., S.Ki; Writing - Review \& Editing, S. Kn, A.S., A.T., S.F., O.G. P.R. and S. Ki. The authors read and approved the final manuscript.

\section{Funding}

This work was supported by the University of Bern and the Swiss Federal Food Safety and Veterinary Office. The funding bodies were not involved in either the design of the study or collection, analysis, and interpretation of data, nor were they involved in writing the manuscript.

\section{Availability of data and materials}

The genome sequence data generated during the current study are available in the GenBank repository under Accession No. CP065521. All other data generated or analyzed during this study are included in this published article.

\section{Declarations}

Ethics approval and consent to participate

No formal ethical approval was needed in this case since all samples investigated were taken for routine diagnostics.

Consent for publication

Not applicable. The animal was owned by the Papiliorama Foundation.

Competing interests

The authors declare that they have no competing interests. 


\section{Author details}

Institute of Veterinary Bacteriology, Vetsuisse Faculty, University of Bern, 122 Laenggassstrasse, CH-3012 Bern, Switzerland. 'Institute of Animal Pathology, Vetsuisse Faculty, University of Bern, 122 Laenggassstrasse, CH-3012 Bern, Switzerland. ${ }^{3}$ Papiliorama Foundation, Moosmatte 1, CH-3210 Kerzers, Switzerland.

Received: 30 December 2020 Accepted: 15 June 2021

Published online: 13 July 2021

\section{References}

1. Bergey DH, Garrity GM, Boone DR, Brenner DJ, Vos Pd, Krieg NR, Goodfellow M. Bergey's manual of systematic bacteriology. 2nd ed. New York: Springer; 2012.

2. Markey B. The Actinobacteria. In: Clinical veterinary microbiology. 2nd ed. Edingurgh: Elsevier; 2013.

3. Barka EA, Vatsa P, Sanchez L, Gaveau-Vaillant N, Jacquard C, Meier-Kolthoff JP, Klenk HP, Clement C, Ouhdouch Y, van Wezel GP. Taxonomy, Physiology, and Natural Products of Actinobacteria. Microbiol Mol Biol Rev. 2016;80(1): $1-43$.

4. Wong VK, Turmezei TD, Weston VC. Actinomycosis. Bmj. 2011;343:d6099.

5. Kononen E, Wade WG. Actinomyces and related organisms in human infections. Clin Microbiol Rev. 2015;28(2):419-42.

6. Stingu CS, Borgmann T, Rodloff AC, Vielkind P, Jentsch H, Schellenberger W, Eschrich K. Rapid identification of oral Actinomyces species cultivated from subgingival biofilm by MALDI-TOF-MS. J Oral Microbiol. 2015;7:26110.

7. Lynch T, Gregson D, Church DL. Species-Level Identification of Actinomyces Isolates Causing Invasive Infections: Multiyear Comparison of Vitek MS (Matrix-Assisted Laser Desorption Ionization-Time of Flight Mass Spectrometry) to Partial Sequencing of the 165 rRNA Gene. J Clin Microbiol. 2016;54(3):712-7.

8. Lawson PA, Falsen E, Akervall E, Vandamme P, Collins MD. Characterization of some Actinomyces-like isolates from human clinical specimens: reclassification of Actinomyces suis (Soltys and Spratling) as Actinobaculum suis comb. nov. and description of Actinobaculum schaalii sp. nov. Int J Syst Bacteriol. 1997;47(3):899-903.

9. Ramos CP, Foster G, Collins MD. Phylogenetic analysis of the genus Actinomyces based on 16S rRNA gene sequences: description of Arcanobacterium phocae sp. nov., Arcanobacterium bernardiae comb. nov., and Arcanobacterium pyogenes comb. nov. Int J Syst Bacteriol. 1997;47(1): 46-53.

10. Nouioui I, Carro L, García-López M, Meier-Kolthoff JP, Woyke T, Kyrpides NC, Pukall R, Klenk HP, Goodfellow M, Goker M. Genome-Based Taxonomic Classification of the Phylum Actinobacteria. Front Microbiol. 2018;9:2007.

11. Hoyles L, Falsen E, Foster G, Pascual C, Greko C, Collins MD. Actinomyces canis sp. nov., isolated from dogs. Int J Syst Evol Microbiol. 2000;50(Pt 4): 1547-51.

12. Castro-Arellano I. Philander opossum. Mamm Species. 2000;638:631-8.

13. O'Connell M. American Opossums. In: MacDonald D, Norris S, editors. MacDonald, D, Norris, S eds: The Encyclopedia of Mammals, vol. 1. London: The Brown Reference Group.; 2006.

14. Sotohira Y, Suzuki K, Otsuka M, Tsuchiya M, Shimamori T, Nishi Y, Tsukano K, Asakawa M. Plasma endotoxin activity in Eastern grey kangaroos (Macropus giganteus) with lumpy jaw disease. J Vet Med Sci. 2017;79(6):1138-41.

15. Michell MA. TTN: Marsupials. In: Manual of Exotic Pet Practice. St. Louis: SAUNDERS Elsevier; 2008. p. 299-325.

16. Woldemeskel M. A concise review of amyloidosis in animals. Vet Med Int. 2012;2012:427296.

17. Kuhnert P, Frey J, Lang NP, Mayfield L. Phylogenetic analysis of Prevotella nigrescens, Prevotella intermedia and Porphyromonas gingivalis clinical strains reveals a clear species clustering. Int I Syst Evol Microbiol. 2002;52(Pt 4):1391-5

18. NCBI BLAST. https://blast.ncbi.nlm.nih.gov/Blast.cgi.

19. Pitcher DG, SN, Owen JR. Rapid extraction of bacterial genomic DNA with guanidium thiocyanate. Lett Appl Microbiol. 1989;8:151-6.

20. Koren S, Walenz BP, Berlin K, Miller JR, Bergman NH, Phillippy AM. Canu: scalable and accurate long-read assembly via adaptive $\mathrm{k}$-mer weighting and repeat separation. Genome Res. 2017;27(5):722-36.

21. Hunt M, Silva ND, Otto TD, Parkhill J, Keane JA, Harris SR. Circlator: automated circularization of genome assemblies using long sequencing reads. Genome Biol. 2015;16:294.
22. Type (Strain) Genome Server. https://tygs.dsmz.de.

23. Meier-Kolthoff JP, Göker M. TYGS is an automated high-throughput platform for state-of-the-art genome-based taxonomy. Nat Commun. 2019;10(1):2182.

24. Lefort V, Desper R, Gascuel O. FastME 2.0: A Comprehensive, Accurate, and Fast Distance-Based Phylogeny Inference Program. Mol Biol Evol. 2015; 32(10):2798-800

25. Meier-Kolthoff JP, Auch AF, Klenk HP, Göker M. Genome sequence-based species delimitation with confidence intervals and improved distance functions. BMC Bioinformatics. 2013;14:60.

26. Lee I, Ouk Kim Y, Park SC, Chun J. OrthoANI: An improved algorithm and software for calculating average nucleotide identity. Int I Syst Evol Microbiol. 2016;66(2):1100-3.

27. Goris J, Konstantinidis KT, Klappenbach JA, Coenye T, Vandamme P, Tiedje JM. DNA-DNA hybridization values and their relationship to whole-genome sequence similarities. Int J Syst Evol Microbiol. 2007;57(Pt 1):81-91.

28. Backert S, Boehm M, Wessler S, Tegtmeyer N. Transmigration route of Campylobacter jejuni across polarized intestinal epithelial cells: paracellular, transcellular or both? Cell Commun Signal. 2013;11:72.

29. Breakpoint tables for interpretation of MICs and zone diameters. http:// www.eucast.org.

30. Samuel JL. Jaw disease in macropod marsupials: bacterial flora isolated from lesions and from the mouths of affected animals. Vet Microbiol. 1983;8(4): 373-87.

31. Li J, Li Y, Zhou Y, Wang C, Wu B, Wan J. Actinomyces and Alimentary Tract Diseases: A Review of Its Biological Functions and Pathology. Biomed Res Int. 2018:2018:3820215.

32. Oh C, Lee K, Cheong Y, Lee SW, Park SY, Song CS, Choi IS, Lee JB. Comparison of the Oral Microbiomes of Canines and Their Owners Using Next-Generation Sequencing. PLoS One. 2015;10(7):e0131468.

33. Rurangirwa FR, Teitzel CA, Cui J, French DM, McDonough PL, Besser T. Streptococcus didelphis sp. nov., a streptococcus with marked catalase activity isolated from opossums (Didelphis virginiana) with suppurative dermatitis and liver fibrosis. Int I Syst Evol Microbiol. 2000;50(Pt 2):759-65.

34. Steininger C, Willinger B. Resistance patterns in clinical isolates of pathogenic Actinomyces species. J Antimicrob Chemother. 2016;71(2):4227.

35. Valour F, Senechal A, Dupieux C, Karsenty J, Lustig S, Breton P, Gleizal A, Boussel L, Laurent F, Braun E, et al. Actinomycosis: etiology, clinical features, diagnosis, treatment, and management. Infect Drug Resist. 2014;7:183-97.

\section{Publisher's Note}

Springer Nature remains neutral with regard to jurisdictional claims in published maps and institutional affiliations.

Ready to submit your research? Choose BMC and benefit from:

- fast, convenient online submission

- thorough peer review by experienced researchers in your field

- rapid publication on acceptance

- support for research data, including large and complex data types

- gold Open Access which fosters wider collaboration and increased citations

- maximum visibility for your research: over $100 \mathrm{M}$ website views per year

At BMC, research is always in progress.

Learn more biomedcentral.com/submissions 